\title{
Emotional words, free recall, and laterality
}

\author{
JUNE A. HAYWARD and K. T. STRONGMAN \\ University of Canterbury, Christchurch, New Zealand
}

\begin{abstract}
Subjects learned lists of emotional and neutral words and were tested with either cued or free recall. Between learning and recall, subjects were required to listen to emotional or nonemotional auditory stimuli. Results demonstrated that cued recall was superior to free recall, memory for emotional words was superior to that for neutral words, and the emotionality of the interpolated material had no effect. These results were analyzed and discussed in terms of the subjects' degree of laterality in an attempt to explicate the role of the two hemispheres in processing emotional material.
\end{abstract}

It has been found in a number of studies on the recall of words from previously seen lists that emotional words have an advantage over neutral words when free recall (FR) is used (e.g., Grosser \& Walsh, 1961; Manning \& Julian, 1975; Strongman, 1982). However, there is no such advantage when recall is cued (e.g., Kleinsmith \& Kaplan, 1963; Walker \& Tarte, 1963).

It may be possible to explain this phenomenon from a neuropsychological perspective. There is abundant evidence, from research with both clinical and normal subjects, that in the vast majority of people verbal processing is a function of the left cerebral hemisphere (for reviews, see Bertelson, 1982; Bradshaw \& Nettleton, 1981; Corballis, 1983) and most emotional processing is carried out in the right hemisphere (for reviews, see Bryden, 1982; Bryden \& Ley, 1983; Campbell, 1982).

The hypothesis of the present study was that FR allows both hemispheres to contribute to the response, producing the emotional word advantage, but that in cued recall (CR) the word search and cue match biases the cognitive processing more strongly toward the left hemisphere, removing the advantage for emotional words.

\section{METHOD}

\section{Design}

Subjects were instructed to learn two lists of emotional and neutral words. The subjects were tested with either CR or FR. Between learning and recall, either a nonverbal emotional sound or a verbal nonemotional sound was played to the subjects, who were required to listen carefully. It was believed that the use of these sounds would enhance the emotional/neutral word dichotomy. The Edinburgh Handedness Inventory (EHI; Oldfield, 1971) was administered to assess the subjects' degree of lateralization, the assumption being that greater use of the left hand in right-handed subjects suggests greater right hemisphere involvement.

\section{Subjects}

Forty-eight males, aged 20 to 24 years, volunteered to take part. All had similar cultural backgrounds and were in at least their third year at university, most of them attending the School of Engineering. As laterality in this context was considered important, right-handed subjects were preferred, but three left-handed subjects were randomly assigned to the

The authors gratefully acknowledge the assistance of N. M. Blampied in the statistical analysis. The authors' address is: Department of Psychology, University of Canterbury, Christchurch 1, New Zealand.
CR condition before their handedness was known. However, since the responses of these subjects were well within the range of the right-handed subjects' responses, they were not replaced.

\section{Apparatus}

A slide projector was used to project words onto a small screen for $2 \mathrm{sec}$ each, with 1-sec breaks between them. The words appeared in white on a dark ground. The sounds were played on a tape recorder. Response sheets were all headed "Memory Experiment." Those for the CR condition had cues typed with a line alongside for the response. The FR response sheets had lines only. A questionnaire, which was the same for both conditions, contained a printed copy of the EHI.

\section{Stimuli}

A separate list was used for each of the two trials. Each list contained 14 words, 7 of which represented emotional categories (sex, violence, and medicine) and 7 of which represented neutral categories (food, leisure activities, and education). These words were rated either very high or very low in emotional content by 52 judges drawn from the same population as the subjects. Cues for each word were constructed to give a clue to the word, but in such a way as to reduce guessing. For example, the cue for singing was words and music; the cue for rape was forced entry. The sounds were rated very high or very low in emotional content by 61 judges from the same population. The nonverbal sound was of an actress making weeping noises. The verbal sound was a visiting politician explaining in a bumbling manner why he had come to New Zealand. Each sound lasted for $20 \mathrm{sec}$.

\section{Procedure}

Subjects were seen singly. They sat at a desk $2 \mathrm{~m}$ from the screen. To minimize extra verbal processing once the procedure had been explained, and if necessary clarified, no discussion was permitted. The first list of words was shown, followed immediately by one of the sounds. A response sheet was given to the subject, who was allowed $3 \mathrm{~min}$ to recall the words. The response sheet was taken and the subject was asked questions about the sound (e.g., "Was the person male or female?"). Then the procedure was repeated with the second list of words and the other sound. Finally the subject filled in the questionnaire. The order of presentation of word lists and sounds was counterbalanced within each condition and subjects were randomly assigned to one condition or the other.

\section{RESULTS}

The numbers of emotional and neutral words for each trial were counted. A laterality quotient (LQ) was calculated for each subject, based on the 10 hand items. Within each condition, the subjects were divided into two groups: high LQ (LQ of 90 or above; $N=10$ in each condition) 
Table 1

Analysis of Variance of Number of Words Recalled

\begin{tabular}{llcc}
\hline \multicolumn{1}{c}{ Source } & $d f$ & MS & $F$ \\
\hline Recall & 1 & 12.323 & $5.44^{*}$ \\
Laterality Quotient & 1 & 7.29 & 3.21 \\
Auditory Stimuli & 1 & .688 & .481 \\
Emotional Loading & 1 & 7.6 & $5.81^{*}$ \\
Recall $\times$ Emotional Loading & 1 & 4.302 & 3.288 \\
Recall $\times$ Laterality $\times$ & 1 & 4.287 & 3.277 \\
$\quad$ Emotional Loading & & & \\
Error & 44 & & \\
\hline
\end{tabular}

${ }^{*} p<.05$.

and low LQ (LQ below 90; $N=14$ in each condition). For the purpose of analysis, the LQ scores of the 3 lefthanded subjects were changed from negative to positive, giving them scores of 100,87 , and 53 , respectively.

Three analyses of variance were performed on the data, using Lane's (1981) program for microcomputers. The first was a $2 \times 2 \times 2 \times 2$ ANOVA with two betweensubjects factors (recall mode and LQ) and two withinsubject factors (auditory stimuli and emotional loading on words). Two main effects, recall mode (FR vs. CR) and emotional loading (emotional vs. neutral), were significant at the 0.05 level. More words were recalled in the CR than in the FR condition, and more emotional than neutral words were recalled (see Table 1). The $F$ ratios of interactions not included on the table were less than one.

Separate ANOVAs were carried out on the FR and CR data. In the FR condition, emotional loading on words was significant at the 0.01 level $[F(1,22)=11.3]$, and the emotional loading-laterality interaction was significant at the 0.05 level $[F(1,22)=5.869]$.

All other main effects and interactions yielded an $F$ value of less than one. In the CR condition, all main effects and interactions also had $F$ values of less than one. Thus, in the FR condition, significantly more emotional than neutral words were recalled. Low LQ subjects recalled greater numbers of emotional than neutral words, whereas high LQ subjects and those in the CR condition recalled similar numbers of emotional and neutral words (see Figure 1).

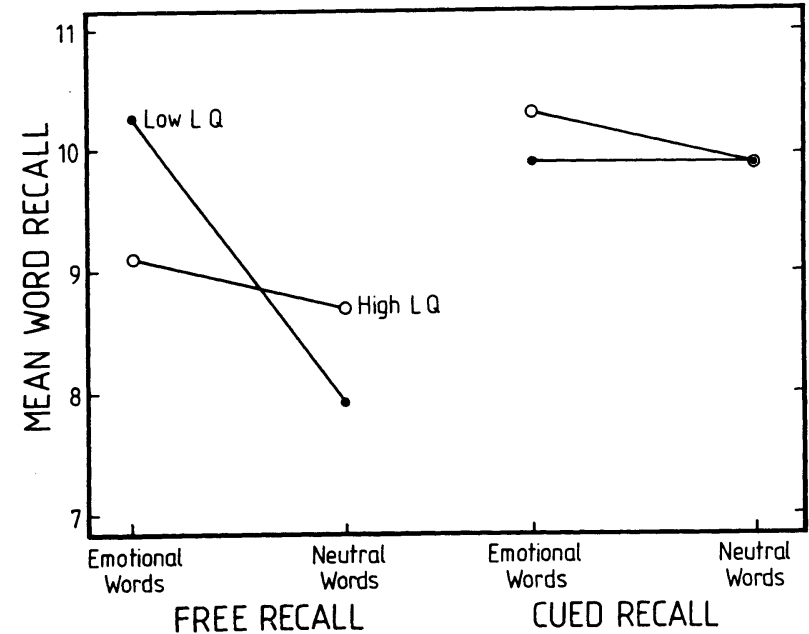

Figure 1. Laterality quotient and word recall (two lists combined).
The main effects for auditory stimuli in the three analyses, together with all the interactions with other factors, show that the sounds had no influence on word recall.

\section{DISCUSSION}

The results show that the subjects in the $\mathrm{CR}$ condition recalled more words than those in the FR condition, which would be expected, since the cues obviously assisted recall. More emotional words than neutral words were recalled. Although the recall mode-emotional loading interaction did not quite reach significance, a possible reason emerged when separate analyses were performed on the two conditions. In the FR condition, it was the low LQ group that was responsible for the emotional word advantage. These subjects not only recalled more emotional words than did the high LQ group, but they also recalled fewer neutral words. This would suggest that the subjects who were less strongly lateralized tended to rely on the emotional connotations of the words as cues to recall. Strongly lateralized subjects may have used verbal strategies to aid recall.

In considering the present results, two caveats should be taken into account. Although the validity and reliability of the EHI are reasonably high (Bryden, 1977; Raczkowski, Kalat, \& Nebes, 1974), the extent to which it reflects relative lateralization of cognitive processes is still open to speculation. Also, the present procedure did not include lateralization of stimulus presentation and response. Nevertheless, support is provided for the hypothesis relating laterality to type of recall with emotional material.

\section{REFERENCES}

Bertelson, P. (1982). Lateral differences in normal man and lateralisation of brain function. International Journal of Psychology, 17, 173-210.

Bradshaw, J. L., \& Nettleton, N. C. (1981). The nature of hemispheric specialisation in man. The Behavior \& Brain Sciences, 4, 51-91.

BRYDEN, M. P. (1977). Measuring handedness with questionnaires. Neuropsychologia, 15, 617-624.

BRYDEN, M. P. (1982). Laterality: Functional asymmetry in the intact brain. New York: Academic Press.

BRYDEN, M. P., \& LEY, R. G. (1983). Right hemisphere involvement in the perception and expression of emotion in normal humans. In K. Heilman \& P. Satz (Eds.), Neuropsychology of human emotion. New York: Guilford Press.

Campbell, R. (1982). The lateralisation of emotion: A critical review. International Journal of Psychology, 17, 211-229.

Corballis, M. C. (1983). Human laterality. London: Academic Press. Grosser, G. L., \& WALSH, A. A. (1966). Sex differences in the differential recall of taboo and neutral words. Journal of Psychology, 63, 219-227.

Kleinsmith, L. J., \& KAPLAN, S. (1963). Paired associate learning as a function of arousal and interpolated interval. Journal of Experimental Psychology, 65, 190-193.

LANE, D. M. (1981). A general analysis of variance program for microcomputers. Behavioral Research Methods \& Instrumentation, 13, 694.

MANNING, S. K., \& Julian, L. (1975). Recall of emotional words. Journal of General Psychology, 92, 237-244.

OLDFIELD, R. C. (1971). The assessment of handedness: The Edinburgh Inventory. Neuropsychologia, 9, 97-113.

RaCZkowski, D., KALAT, J. W., \& NebES, R. (1974). Reliability and validity of some handedness questionnaire items. Neuropsychologia, 12, 43-47.

Strongman, K. T. (1982). Emotional influences on memory. Current Psychological Research, 2, 69-74.

WALKER, E. L., \& TARTE, R. D. (1963). Memory storage as a function of arousal and time with homogeneous and heterogeneous lists. Journal of Verbal Learning \& Verbal Behavior, 2, 113-119.

(Manuscript received for publication December 16, 1986.) 